\title{
Current Research Interests and Presentation Proposals
}

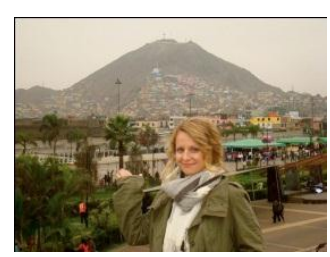

Katie McClintic

Using Social Issues and Social Media to Inspire Language Learning

Teachers in large language programs such as ours often struggle with motivating our students to communicate in the target language. One way to do this is by using a content based approach for designing class lessons. More specifically, using content about global issues can not only help motivate students to communicate but also engage them on an emotional level. Incorporating topics dealing with global issues can motivate students to not just communicate their original opinions in the target language, but more importantly to think deeply about complex topics. This also serves to help students develop the critical thinking skills necessary to be successful students at an American university.

Another challenging aspect of teaching a generation of digital natives is keeping students engaged. In an age of Facebook facilitated revolutions and breaking news spreading at the speed of Twitter, opportunities exist for broadening student understanding of social issues through various interactive, multi-media platforms. Not only can students get up-to-the-minute updates on the content, but this level of interaction can keep students engaged in the learning process and provide real motivation for communicating in English.

Finally, by encouraging students to work collaboratively to create multi-media projects, and then share their projects with each other (or with a broader audience if they so choose), students can see in real time the power of their ideas AND the power of information spread in English. To get an example of how these ideas might be translated into an actual class lesson(s), you can explore a sample lesson entitled "The World Water Crisis" built through Google sites. The site provides an example of how one might scaffold a lesson by blending technology and in-class work. The site takes students through various steps of the learning process, from activating prior knowledge, introducing the topic with a web quest, and allowing students to learn more extensively about the topic through reading. In addition, you will find a sample rubric for assessing group work as well as a more detailed sample lesson plan. A number of additional teacher resources for using technology in class have also been included on the site. If you would like to hear more about the theoretical foundations to this approach, you can listen to the recorded presentation from the Philadelphia 2012 TESOL conference (just click on the link in the "Resources for Teachers" page).

Return to Table of Contents 


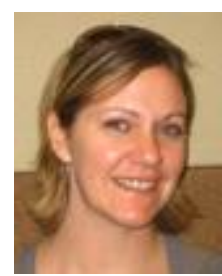

Summer Marvin

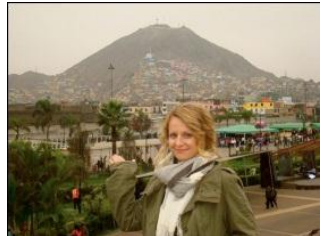

Katie McClintic

It's Alive! Blending Technology with Academic Materials for Engaged Learning

With the rise in Web 2.0-based tools being used in classrooms, the traditional teaching model of Presentation, Practice, and Production is quickly being pushed aside in favor of a "flipped" approach to teaching. A "flipped" lesson, made more widespread with the use of sites like Khan Academy and TEDed, allows teachers to focus more on interacting with students and problem-solving because students have already been presented with the lesson before entering the physical classroom. In other words, students construct meaning about topics outside the classroom, thus giving teachers more time to focus on guiding students in accomplishing a task.

Our research focuses on identifying and demonstrating specific ways to rejuvenate content-based academic materials using Web 2.0 tools such as Weebly, Google Sites, Quizlet, Online Magazines, and TED-Ed in an effort to maximize in-class learning while allowing students to negotiate meaning and learn autonomously. Our goals include empowering and equipping other teachers with appropriate resources and effective techniques for blending technology and pedagogy responsibly to suit the needs of the techsavvy digital natives that are filling up today's classrooms. Our work is based on current academic experiences as we have endeavored to blend technology and pedagogy while meeting course specific outcomes in the IEP environment.

\section{Return to Table of Contents}

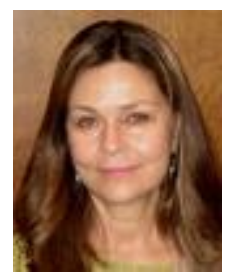

Barbara L. Yoder

\section{Issues in Teaching Visual Culture to University ESL Students}

University art museums are challenged to cultivate culturally diverse audiences, including university ESL students. At the same time, university ESL teachers are challenged to provide students with authentic academic experiences that reinforce language skills and stimulate critical thinking. It is surprising then that scant attention has been paid to the potential for art museum-IEP collaborations when both sides have much to gain. As both an ESL teacher and art museum educator, I am working with Spencer Museum of Art staff to develop English for Academic Purposes materials that focus on visual culture. The collaboration brings together my two professions, TESL and art museum education. In addition to teaching at the Applied English Center, I write educational materials for museum exhibitions sponsored by the National Endowment for the Arts and the National Endowment for the Humanities. 


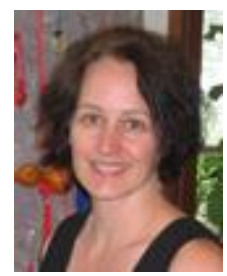

Sandra Issa

Increasing Returns on Your Investment: Making Feedback Work

Writing instructors often devote hours to writing comments on students' papers only to find that the feedback is ignored in subsequent assignments. Why does this happen? How can we get students to incorporate the feedback we give them into future drafts and assignments? My session will present the findings of a two-part study exploring student responses to different kinds of feedback and exploring the ways in which instructors introduce feedback to students. I will share strategies for introducing and providing feedback that students will use based on the results of the study and research in the literature. Participants will leave the session with specific ideas about how to make their feedback more accessible, useful, and understandable to students.

\section{Return to Table of Contents}

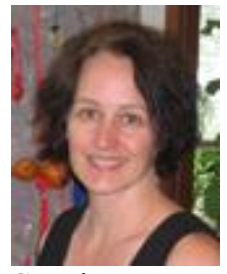

Sandra Issa

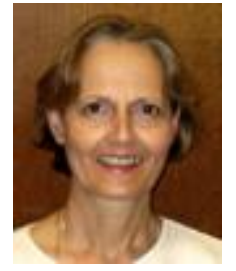

Mary McGuinness

\section{Student Complaints about Faculty: Where to Start, Where to Go}

What do you do if a student brings you a complaint about an instructor? Such complaints can create uncomfortable situations for students, instructors, and administrators. However, they can offer a learning experience for everyone involved. What are the first steps that should be taken when a student makes a complaint? What kind of follow-up is necessary? How do you create a system for handling complaints that works in everyone's best interests? We will address causes for student complaints, provide strategies for discussing the complaints with students and with instructors, and offer suggestions on how to establish procedures for handling these types of complaints.

Return to Table of Contents 


\section{SPECIAL ISSUE: Call for ideas on Teaching Vocabulary}

How do YOU teach vocabulary? How do coordinators handle vocabulary for the different levels and skills? How is vocabulary taught at the AEC? This is a call for essays, articles, thoughts, opinions, materials, and/or strategies on how vocabulary is taught at the AEC and/or how vocabulary should be taught here. Please submit your approach to teaching vocabulary to me directly: mberardo@ku.edu.

\section{Return to Table of Contents}

\section{Copy Editor: Service Opportunity}

Issues in Language Instruction at the Applied English Center: A Journal for Practicing and Interpreting TESL at the University of Kansas is looking for a copy editor.

This is an opportunity for service to the AEC. There is no compensation other than the excitement of working with our colleagues' latest thoughts on practicing and interpreting TESL at the University of Kansas. If interested please contact me: mberardo@ku.edu. 